\title{
CLINICAL AND RADIOGRAPHIC OUTCOMES OF POLY- ETHERETHERKETONE (PEEK) HYBRID PROSTHESIS USED FOR "ALL ON FOUR" REHABILITATION OF EDENTULOUS MAXILLA. A SHORT-TERM CASE SERIES STUDY
}

\author{
Samer Mostafa $\mathrm{Ali}^{*}$ and Dina Bahgat El Talawy**
}

\begin{abstract}
Purpose: The aim of this study was to evaluate clinical and radiographic outcomes of polyetheretherketone (PEEK) hybrid prosthesis used for "All on four" rehabilitation of edentulous maxilla.

Materials and methods: Six patients with atrophied edentulous maxillary ridges were managed by 4 implants according to the "All on four" protocol using computer guided surgery and flapless surgical approach. The existing maxillary dentures were placed immediately after modifications on the same day. After 6 months, the definite prosthesis consisted of screw retained milled BioHPP framework bonded to acrylic resin teeth and denture base. The prosthesis restored lost teeth, hard and soft tissues (hybrid fixed prosthesis). Plaque and gingival index, probing depth, implant mobility and bone loss (measured by standardized periapical radiographs) were evaluated after prosthesis delivery (T0), six months (T6) and 12 months (T12) after delivery.
\end{abstract}

Results: Two implants failed in one patient resulting in $91.7 \%$ survival rate. Plaque index increased with time. No difference in gingival index, pocket depth, implant stability, and vertical bone loss between observation times was noted. Posterior implant showed higher plaque scores and pocket depth than anterior implants after 6 and 12 months and no significant difference in all other parameters between anterior and posterior implants was noted.

Conclusion: Within the limitation of this study, PEEK hybrid prosthesis bonded to acrylic resin teeth and denture base can be used successfully to rehabilitate patients with atrophic maxilla according to "All on four" concept as it was associated with favourable clinical and radiographic outcomes after one year.

* Associate Professor, Department of Removable Prosthodontics, Faculty of Dentistry, Modern Science and Arts University (MSA), Egypt

** Associate Professor, Department of Removable Prosthodontics, College of Oral and Dental Surgery, Misr University For Science and Technology, Egypt. 


\section{INTRODUCTION}

One of the major challenges facing dentistry has been rehabilitation of atrophic maxillary jaws ${ }^{1}$. Immediate implant-supported rehabilitation of edentulous jaws has been reported to provide a reliable alternative to conventional dentures while significantly improving quality of life for edentulous patients $^{2,3}$. However, with maxillary atrophy augmentation surgery, regardless of reconstructive procedure, carries a higher risk of patient morbidity and complications (e.g., infection, loss of graft material) as well as higher cost and longer time interval to complete the treatment ${ }^{4}$.

The concept of the all-on-four is to insert 4 implants in the anterior part of the ridge to assist a temporary, fixed, and immediately loaded bridge. The anterior 2 implants are installed vertically, and the posterior 2 fixtures are inserted with distal inclination to decrease the cantilever length and permit the use of prosthesis with 10 to 12 teeth $^{5,6}$. Final prosthesis may be fixed or hybrid screw retained prosthesis ${ }^{7}$.With All-on-Four treatment, bone augmentation and sinus lift are omitted. Furthermore, restoration support is improved due to increasing the antroposterior spread and shortening of cantilevers which provide optimum load sharing. Moreover, the immediate function concept represents a major advantage for patients, providing less time-consuming treatment ${ }^{8,9}$. Several types of final prosthesis were reported to be used with the All on four implant concepts. They include metal ceramic or metal acrylic permanent prosthesis, or final prosthesis remained in acrylic resin ${ }^{10,11}$.

The substructure framework material for full arch fixed implant supported prosthesis include; cast gold/nickel chromium material, milled titanium or zirconium frames using computer aided-design/computed aided-manufacture (CAD/ CAM) technology ${ }^{12}$. However, these materials are very stiff and lack shock absorption which may transfer high forces to the implant via the superstructure $^{13}$. Polyetheretherketone (PEEK) is a high-performance thermoplastic polymer which can be utilized as a metal substitute for fixed and removable restoration. This material has several advantages such as strength to weight ratio, corrosion resistance, biocompatibility, compatibility with medical imaging, low plaque affinity and chemical stability $^{14-16}$. Moreover, it has good mechanical behavior, creep, wear resistance and shock absorbing ability ${ }^{13}, 17$. These criteria make the PEEK material a useful substitute to metal frameworks for fixed implant supported restorations. PEEK is radiolucent, which facilitate identification of screw loosening by periapical radiograph. PEEK has also a low specific weight that allow construction of lighter prosthesis, providing high patient satisfaction and comfort during function ${ }^{18}$. The PEEK material can be fabricated by either computer aided design/ computer aided manufacturing (CAD/CAM) or by injection molding ${ }^{18}$

PEEK material was modified by adding $20 \%$ ceramic fillers (High performance polymer, BioHPP; bredent $\mathrm{GmbH} \& \mathrm{Co} \mathrm{KG}$ ) to increase the modulus of elasticity. BioHPP is elastic as bone, act as a stress breaker and reduce the occlusal forces transferred to the restoration and opposing dentition ${ }^{19}$. Moreover, it has high bond strength to acrylic resin (polymethyl methacrylate) and to indirect composite resin ${ }^{20,21}$ through primer provided by the manufacture (visio. link; bredent $\mathrm{GmbH} \& \mathrm{Co} \mathrm{KG}$ ). When BioHPP used for implant frameworks, it can be veneered with acrylic resin denture teeth or light-polymerized indirect composite resin ${ }^{18}$.

Reviewing the literature, the clinical evaluation of PEEK implant supported full arch fixed hybrid prosthesis especially for All on four prosthesis is scarce $^{12}$. Therefore, the aim of the present study was to evaluate clinical and radiographic outcomes of polyetheretherketone (PEEK) hybrid prosthesis used for "All on four" rehabilitation of edentulous maxilla. 


\section{MATERIALS AND METHODS}

Six individuals ( 3 males and 3 females) with mean age of $60 \pm 4.1$ years were enrolled in the current study. The patients had completely edentulous maxilla and implant overdentures in the mandibular jaw. The participants had atrophic maxillary ridges with maxillary sinus pneumatization and insufficient bone in maxillary posterior ridges to receive standard implants of adequate length. They all suffered from lack of retention and stability of maxillary dentures and need a fixed prosthesis in maxilla, 2) sufficient bone height and width in the anterior maxillary area between the maxillary sinuses to receive four implants according to the All on four protocol with dimensions (at least $12 \mathrm{~mm}$ long and $3.8 \mathrm{~mm}$ wide). The exclusion criteria were: 1) blood disorders, 2) autoimmune diseases, 3) uncontrolled diabetes mellitus, 4) metabolic diseases affecting bone, 5) irradiation of the head or neck region in the last 2 years, and 6) inadequate oral hygiene performance. The patients were instructed about the treatment protocol and objectives prior to obtain an informed consent. The study was conducted according the ethical principles of Helsinki Declaration (https:// www.wma.net/).

\section{Surgical and prosthetic procedures}

All selected patients received new maxillary and mandibular dentures (CD). After 2-month adaptation period, gutta-perchae markers were embedded to the polished surface of the maxillary denture at labial, vestibular and palatal flanges. Dual scan protocol was followed using cone beam CT (CBCT, i-CAT, Imaging Sciences International ISI, Pennsylvania, USA), Firstly, the patients were scanned while wearing their maxillary denture with gutta-perchae radiopaque markers, then the maxillary dentures were scanned alone on the table of the CBCT machine (with long axis of the denture is in line with long axis of the table. The data sets of the double scans were overlapped then the acquired images were loaded into 3-D image treatment planning software (OnDemand). According to the CT scan, the implants were virtually planned according to the All On four protocol, with correct position and orientation of the implants relative to vital structures (maxillary sinuses, naso-incisive canal and nasal cavity). The anterior 2 implants were planned at lateral incisor or canine areas (13mm in length and $3.7 \mathrm{~mm}$ in diameter) with slight labial inclination to account for labial inclination of premaxillary bone and the implants were set parallel to each other as possible in the coronal plane. The posterior 2 implants $(15 \mathrm{~mm}$ in length and $3.7 \mathrm{~mm}$ in diameter) are planned to be distally inclined by $30^{\circ}$ and positioned just anterior to the maxillary sinuses and engage the cortical bone of the anterior sinus wall for increased stability. The posterior implants were planned to emerge in the mesial cusp region of the first molar tooth. This arrangement allowed for good implant anchorage, short cantilever length, and large interimplant distance ${ }^{5,22}$. Based on this plane, stereolithographic surgical guide was constructed using prototyping technique for each participant. Virtual model planning software was used to define the sites for implant placement and anchor pins for the surgical guide. A mucosal supported stereolithographic surgical template (fig.1) with 4 sleeves positioned over proposed implant sites was constructed using 3D printing technology (In2Guide).

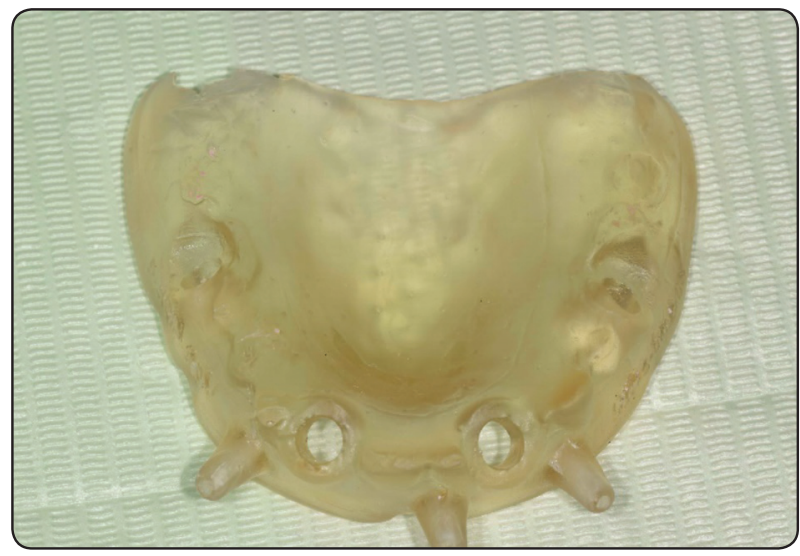

Fig. (1) Mucosal supported stereolithographic guide 
All patients were premedicated with diazepam before operation. Antibiotics (amoxicillin 625mg + clavulanic acid 125mg, Augmentin ${ }^{\circledR} 1 \mathrm{gm}$ ) were prescribed before surgery and continued 6 days later. Corticosteroids (Dexamethazone ${ }^{\circledR}$ ) was injected immediately after surgery to reduce postoperative edema and inflammation. Antiinflammatory medication (ibuprofen ${ }^{\circledR}, 600 \mathrm{mg}$ ) was administered for 5 days postoperatively. Analgesics (Ketolac ${ }^{\circledR} 10 \mathrm{mg}$ ) were given on the day of surgery and postoperatively for the first 5 days. The surgery was made according the flapless protocol under local anesthesia using partial guided protocol. Four implants (Biohorizon, Irvine, California, USA) were inserted using the surgical guide and the universal surgical kit (In2Guide, Universal Kit Cybermed Inc) supplied with the mucosal supported stereolithographic surgical template to be used during osteotomy preparation (fig. 2). This kit includes hand drill sleeves with successive increasing diameters that fit the template holes (in the same diameter of sleeves). The hand sleeves were used during consecutive drilling procedures with surgical guide to accommodate the successive increase in drill diameter. The template was stabilized in the patient's mouth by a rubber base interocclusal record and fixed to the maxillary bone using anchor pins. The minimum torque at implant placement was $40 \mathrm{Ncm}$ to permit immediate loading of the implants ${ }^{23}$. 17-degree angled multiunit abutments (Biohorizon, Irvine, California, USA) were screwed to the lateral incisor/canine implants and 30-degree multiunit abutment were screwed to premolar implants at $20 \mathrm{Ncm}$ torque. Implants were immediately loaded by existing maxillary dentures. The denture was modified by removal of the labial, buccal flanges and the palate (leaving only $10 \mathrm{~mm}$ of acrylic denture base in a horseshoe manner). Also the second molar artificial teeth were removed $^{24}$. Temporary metal caps were screwed to the multiunit abutments. The denture base opposite to the multiunit abutments was hollowed. Rubber dam sheet was fastened to the abutments. The temporary metal caps were picked up to the modified denture using auto polymerized acrylic resin (fig.3). The occlusal contact of first molar with opposing denture was removed to relieve the pressure on the inclined posterior implants. Postoperative medications include analgesics to relieve pain, systemic antibiotic cover (amoxicillin and clavulanic acid (Augmentin ${ }^{\circledR} 1 \mathrm{gm}$ ) for 17 days, a chlorhexidine digluconate $0.2 \%$ mouth rinse for 2 weeks and direct application of anti-inflammatory gel to the peri-implant area. Anti-inflammatory medication was prescribed post surgically from days 5 to 10. Participants were informed to eat soft diet and avoid hard foods. Participants were instructed for oral hygiene procedures and informed to attend regular follow-up visits to verify oral hygiene practice and perform adjustments of the relined dentures till osseointegration occurs.

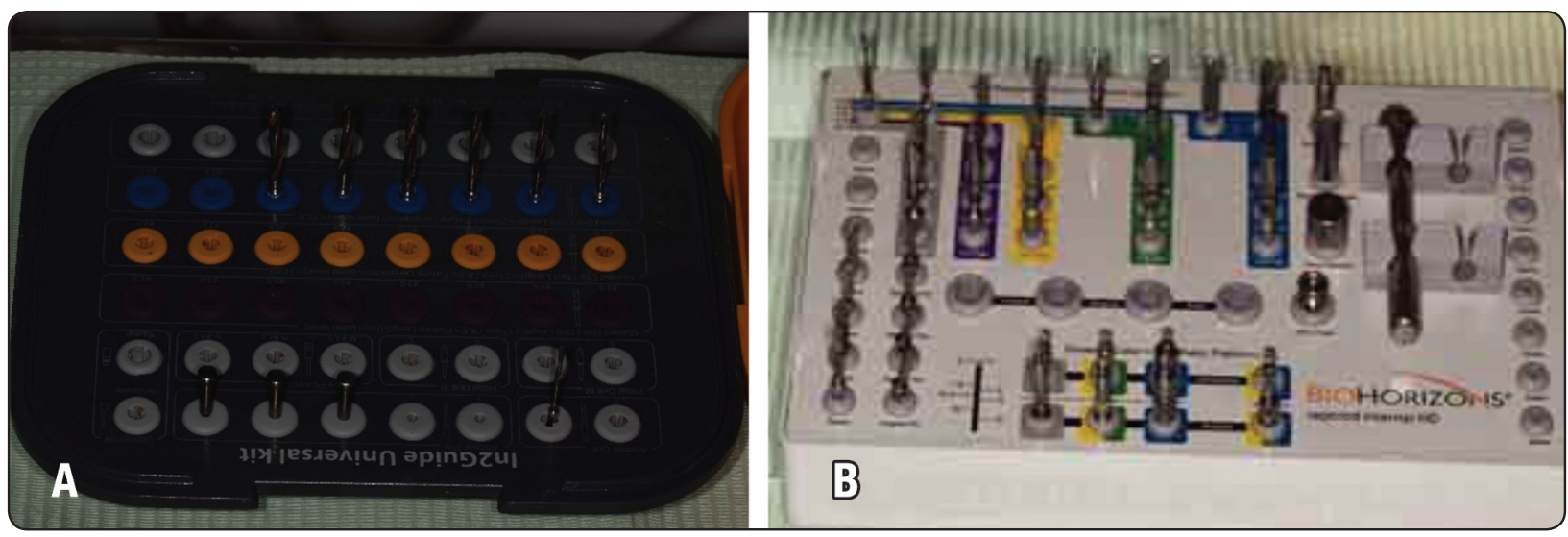

Fig 2. (A) In2Guide surgical kit. (B) The surgical kit of Biohorizon system 


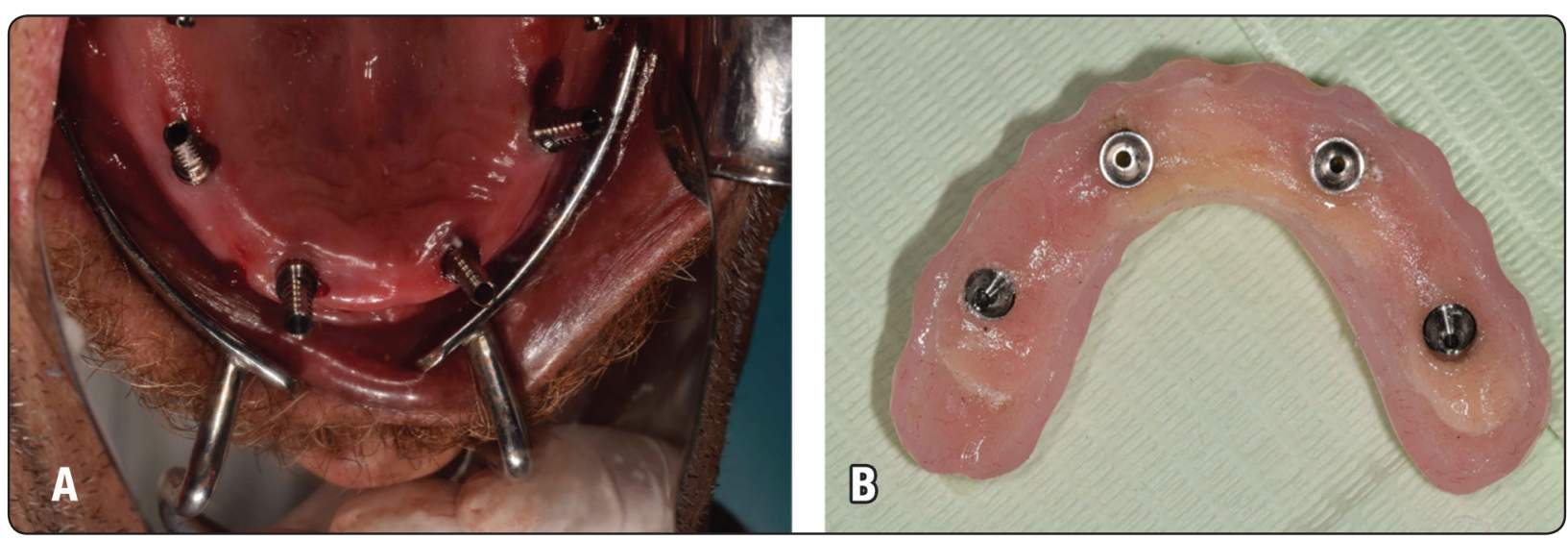

Fig. (3) Immediate loading of the implants by provisional denture.

After 3 months of osseointegration period, open tray impression procedure was started. The provisional acrylic denture was un-screwed from the multi-unit abutments. The abutment level long transfer copings were screwed to the multi-unit abutment and splinted with Duralay (Duralay, Reliance Dental MFG Co, Worth, IL, USA) acrylic resin to prevent movement of the transfer coping during impression procedure. A stock tray was perforated over the transfer coping to allow unscrewing of the transfers after impression making. Light body rubber base impression (Zhermack ${ }^{\circledR}$, Badia Polesine, Rovigo, Italy) was injected around the transfer coping. The tray was filled with heavy body impression material and placed, such that the guide pins are identified. The long transfer copings were unthreaded and the impression was removed from patient mouth. Implant analogues were fastened to the copings and the impression was now poured to obtain master cast. Metal caps were screwed to the abutment analogues on the master cast. Record blocks were fabricated on the casts and used to record jaw relationship. Appropriate lip support was restored. The cast was scanned using a CAD/CAM device (Ceramill Map400, Amann Girrbach AG. Koblach, Austria), then a fixed prosthesis that replace lost teeth and gingival tissues was designed using the software of the device. The fixed partial denture was milled in Polyether-
etherKetone (PEEK) BioHPP (high performance polymer) discs (Bredent $\mathrm{GmbH} \&$ Co.KG, Weißenhorner Str. 2, 89250 Senden, Germany). The milled frame was fixed to the metal caps using resin cement on the master cast. The BioHPP framework was tried in patient mouth for passive fit (fig 4). Wax interocclusal record was made to establish the occlusal relationship with opposing teeth. Acrylic resin teeth veneers were arranged in the wax for try in. If needed the BioHPP frame was adjusted to accommodate resin teeth.

The occlusal scheme was bilateral balanced occlusion to enhance the stability of mandibular implant overdentures. The BioHPP framework was painted with appropriate adhesive provided by the

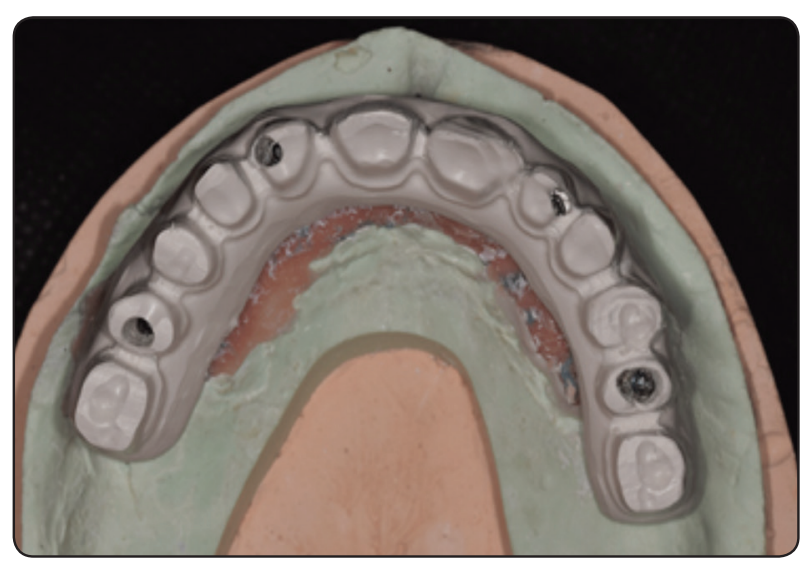

Fig. (4) Milled BioHPP framework for the fixed prosthesis on the cast. 
manufacture (visio.link; bredent $\mathrm{GmbH} \& \mathrm{Co} \mathrm{KG}$ ). The frame was flasked on the cast and acrylic resin that restore lost gingival tissue were packed over the frame, finished and polished. The maxillary prosthesis (which consisted of BioHPP framework, acrylic resin teeth and pink acrylic gingival tissues) was delivered to the patients (fig.5) with emphasis on oral hygiene procedure and follow-up visits to make necessary adjustments.

\section{Clinical and radiographic evaluations}

Clinical and radiographic evaluations of periimplant tissues were performed after prosthesis delivery (T0), six months (T6) and 12 months (T12) after delivery. Plaque index and gingival index were evaluated using the Mombelli indices ${ }^{25}$. A graduated plastic probe was used to measure the pocket depth in $\mathrm{mm}{ }^{26,27}$. Implant stability measurements was recorded using resonance frequency analysis. The Osstell device (Integration Diagnostics Ltd.) expresses the mobility as implant stability quotient. The multiunit abutments were removed and smart pigs of the Ostell device were connected to the internal hex of the implants. Plaque index, gingival index and probing depth were measured at the midfacial, mid-lingual, mid-mesial, and mid-distal aspects of each fixture.

Peri-implant bone evaluation was made using long cone paralleling technique and periapical

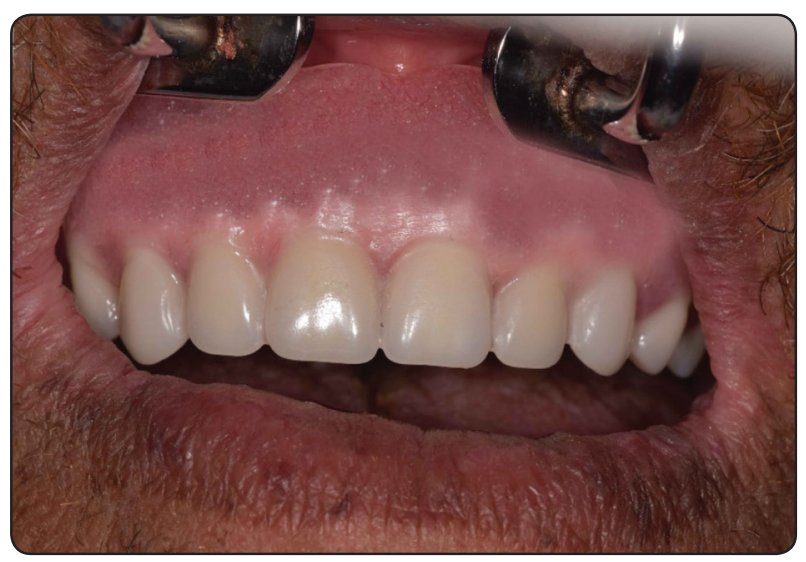

Fig. (5) Final prosthesis in the patient mouth radiography captured by a digital device (Digora, Soredex). A film holder designed specifically for implant imaging (Hawe Neos Dental CH-6934, Bioggio, Switzerland) were used for intraoral radiograph. To maintain the same film-implant distance and cone implant distance, the film holder was fixed to customized acrylic interocclusal jig to obtain standardized radiographs. The digital images were traced using the accompanying software and bone resorption was measured as the distance between implant-abutment junction and first bonecontact(fig.6) ${ }^{26-29}$. To compensate for magnification errors, the known implant length and width were used to correct readings on the images to their actual values. Bone resorption was averaged from mesial and distal aspects of each implant.

\section{Statistical analysis}

The data were explored for normality of distribution. The data was non-parametric and violated the normal distribution. Descriptive statistics of plaque and gingival scores were presented as median (Med), minimum (mini), and maximum (maxi). On the other hand, the descriptive statistics of pocket depth, implant stability and bone loss were presented as mean (X) and standard deviation (SD). The difference in clinical and radiographic parameters between observation times was detected using Friedman test followed by

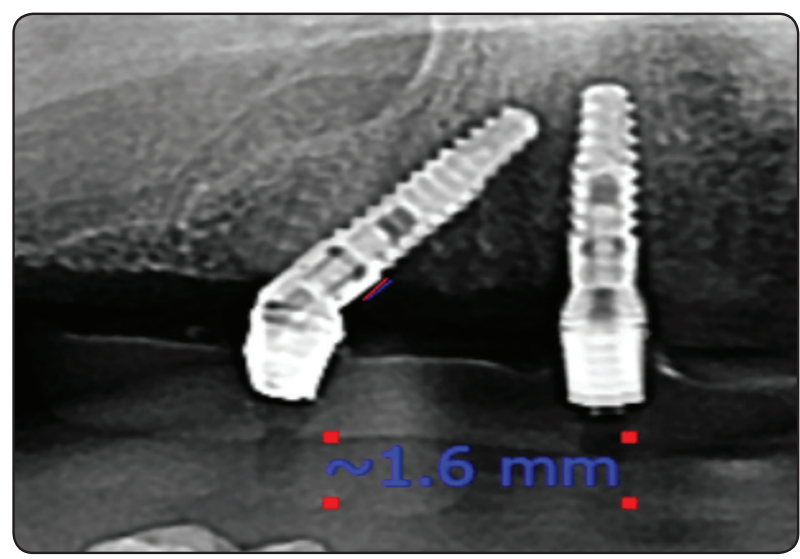

Fig. (6) Peri-implant alveolar bone evaluation 
Wilcoxon signed ranks test for pair-wise comparison between observation times. Mann Whitney test was used to compare clinical and radiographic outcomes between anterior and posterior implants. The data were analyzed using SPSS ${ }^{\circledR}$ software version 25 (SPSS Inc., Chicago, IL, USA). P-values $<0.05$ were considered to be significant.

\section{RESULTS}

Two implants failed in one patient resulting in 91.7\% survival rate. The failed implants were the distal (inclined) implants on each side of the patient and the failure occurred in the first 3 months after loading with provisional dentures.

The failed implants were replaced by newer implants of increasing diameters (width and length) and left submerged to integrate without loading and they were included in the support of the final prosthesis. The 2 implant failures were due to implant overload and they were mobile only, and not associated with infection or suppuration but the implants were associated with pain on pressure. None of the implants were associated with abscess or fistula formation. The patient with failed implants was omitted from the study.

Comparisons of tested parameters between time intervals for anterior and posterior implants are shown in table 1 and table 2 respectively. Anterior and posterior implants showed significant increase of plaque index with time $(\mathrm{p}<.001)$. No difference in gingival index, pocket depth, implant stability, and vertical bone loss between observation times

Table (1) Comparison of tested parameters between time intervals for anterior implants

\begin{tabular}{|c|c|c|c|c|}
\hline & T0 & T6 & T12 & $\begin{array}{c}\text { Freidman test } \\
\text { (p value) }\end{array}$ \\
\hline \multicolumn{5}{|c|}{ Plaque indices } \\
\hline Med(Mini-Maxi) & $.00(.00-1.00)$ & $.00(.00-.200)$ & $1.00(1.00-3.00)$ & $.005 *$ \\
\hline \multicolumn{4}{|l|}{ Wilcoxon signed ranks } & \\
\hline Test & & \multicolumn{2}{|c|}{$.032 *$} & \\
\hline (p value) & \multicolumn{3}{|c|}{$.009 *$} & \\
\hline \multicolumn{5}{|c|}{ Gingival indices } \\
\hline Med(Mini-Maxi) & $.00(.00-.00)$ & $.00(.00-.00)$ & $0.00(.00-.00)$ & 1.00 \\
\hline \multicolumn{4}{|l|}{ Wilcoxon signed ranks } & \\
\hline Test & & \multicolumn{2}{|c|}{1.00} & \\
\hline (p value) & \multicolumn{3}{|c|}{1.00} & \\
\hline \multicolumn{5}{|c|}{ Probing depth } \\
\hline $\mathrm{X} \pm \mathrm{SD}$ & $1.49 \pm .37$ & $1.53 \pm .54$ & $1.61 \pm .56$ & .067 \\
\hline \multirow{3}{*}{$\begin{array}{c}\text { Wilcoxon signed ranks } \\
\text { Test } \\
\text { (p value) } \\
\end{array}$} & \multicolumn{2}{|c|}{.21} & & \\
\hline & & \multicolumn{2}{|c|}{.18} & \\
\hline & \multicolumn{3}{|c|}{.087} & \\
\hline \multicolumn{5}{|c|}{ Implant stability } \\
\hline $\mathrm{X} \pm \mathrm{SD}$ & $65.55 \pm 1.57$ & $65.1 \pm 1.78$ & $66.30 \pm 1.69$ & .11 \\
\hline \multirow{3}{*}{$\begin{array}{c}\text { Wilcoxon signed ranks } \\
\text { Test } \\
\text { (p value) } \\
\end{array}$} & \multicolumn{2}{|c|}{.84} & & \\
\hline & & \multicolumn{2}{|c|}{.75} & \\
\hline & \multicolumn{3}{|c|}{.23} & \\
\hline \multicolumn{5}{|c|}{ Bone resorption } \\
\hline $\mathrm{X} \pm \mathrm{SD}$ & - & $.86 \pm .54$ & $.91 \pm .46$ & \\
\hline $\begin{array}{c}\text { Wilcoxon signed ranks } \\
\text { Test ( } \mathrm{p} \text { value) }\end{array}$ & & & & \\
\hline
\end{tabular}

*= significant at .05 level 
was noted. Multiple comparisons of each 2-time intervals are presented in the same tables.

Comparisons of tested parameters between anterior and posterior implants at different time intervals are shown in table 3. Posterior implant showed higher plaque scores and pocket depth than anterior implants after 6 and 12 months. No difference in gingival scores, implant stability and bone loss between anterior and posterior implants was noted after 6 and 12 months.

TABLE (2) Comparison of tested parameters between time intervals for posterior implants

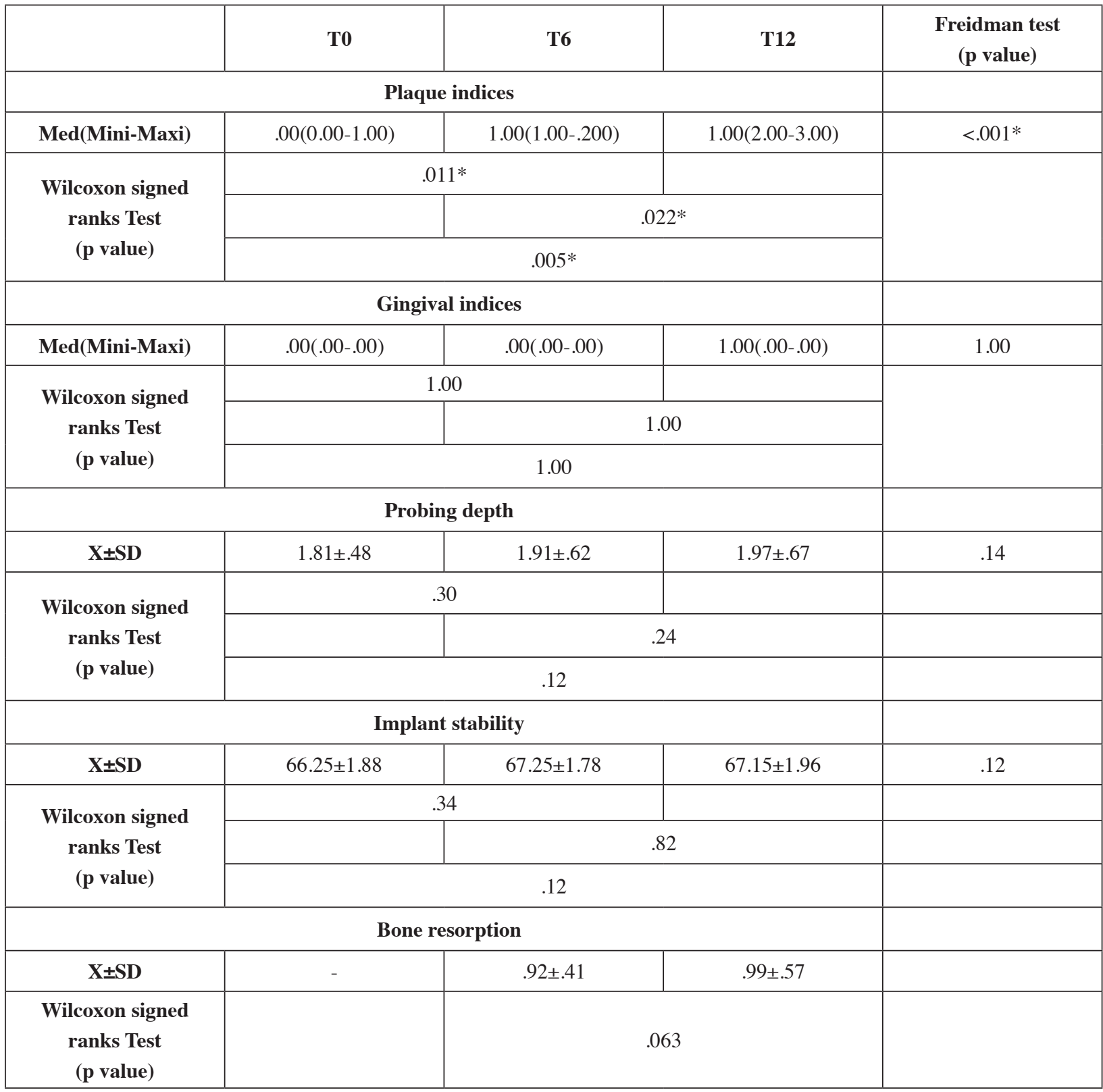

$*=$ significant at .05 level 
TABLE (3) Comparisons of tested parameter between anterior and posterior implants at different time intervals

\begin{tabular}{|c|c|c|c|}
\hline & T0 & T6 & T12 \\
\hline \multicolumn{4}{|c|}{ Plaque scores } \\
\hline Anterior implants Med(Mini-Maxi) & $.00(.00-1.00)$ & $.00(.00-.200)$ & $1.00(1.00-3.00)$ \\
\hline Posterior implants Med(Mini-Maxi) & $.00(0.00-1.00)$ & $1.00(1.00-.200)$ & $1.00(2.00-3.00)$ \\
\hline Mann Whitney test(p value) & .98 & $.033 *$ & $.002 *$ \\
\hline \multicolumn{4}{|c|}{ Gingival scores } \\
\hline Anterior implants Med(Mini-Maxi) & $.00(.00-.00)$ & $.00(.00-.00)$ & $0.00(.00-.00)$ \\
\hline Posterior implants Med(Mini-Maxi) & $.00(.00-.00)$ & $.00(.00-.00)$ & $1.00(.00-.00)$ \\
\hline Mann Whitney test ( $p$ value) & 1.00 & 1.00 & .34 \\
\hline \multicolumn{4}{|c|}{ Probing depth } \\
\hline Anterior implants $\mathrm{X} \pm \mathrm{SD}$ & $1.49 \pm .37$ & $1.53 \pm .54$ & $1.61 \pm .56$ \\
\hline Posterior implants $\mathrm{X} \pm \mathrm{SD}$ & $1.81 \pm .48$ & $1.91 \pm .62$ & $1.97 \pm .67$ \\
\hline Mann Whitney test ( $p$ value) & $.021 *$ & $.031 *$ & $.040 *$ \\
\hline \multicolumn{4}{|c|}{ Implant stability } \\
\hline Anterior implants $\mathrm{X} \pm \mathrm{SD}$ & $65.55 \pm 1.57$ & $65.1 \pm 1.78$ & $66.30 \pm 1.69$ \\
\hline Posterior implants $\mathrm{X} \pm \mathrm{SD}$ & $66.25 \pm 1.88$ & $67.25 \pm 1.78$ & $67.15 \pm 1.96$ \\
\hline Mann Whitney test (p value) & .14 & .07 & .18 \\
\hline \multicolumn{4}{|c|}{ Bone resorption } \\
\hline Anterior implants $\mathrm{X} \pm \mathrm{SD}$ & & $.86 \pm .54$ & $.91 \pm .46$ \\
\hline Posterior implants $\mathrm{X} \pm \mathrm{SD}$ & & $.92 \pm .41$ & $.99 \pm .57$ \\
\hline Mann Whitney test (p value) & & .24 & .51 \\
\hline
\end{tabular}

*= significant at .05 level

\section{DISCUSSION}

The palatal flanges of the existing maxillary denture were left to provide rigidity and minimize maxillary denture base fracture. The modified denture was similar to the provisional fixed acrylic partial denture used in the original protocol of $\mathrm{Malo}^{6}$. In the current study, PEEK material was used as a framework for the prosthesis instead of using cast nickel chromium or milled Zirconium or titanium frames. Although metal frameworks are rigid, present good mechanical properties, and provide the ability to be sectioned and reconnected in case of misfits, it has high modulus of elasticity which cause mechanical complications such as porcelain fractures, screw loosening, metal warping while firing the porcelain which cause misfit ${ }^{18}$. Zirconia frameworks are biocompatible, have low bacterial adhesion, with good mechanical properties. However, it possesses inability to cut and reconnect in the case of misfits, and are associated with high rates of porcelain fractures or chipping. PEEK framework in this study combined with polymethyl methacrylate acrylic teeth has low modulus of elasticity than metal or zirconium 
frameworks combined with porcelain which further dampen the occlusal forces and have a beneficial effect especially when used for implant restorations where proprioception is reduced by the absence of periodontal ligaments ${ }^{18,30}$. In case of misfit, metal sleeves can be sectioned and reconnected to the PEEK frame in the patient mouth using resin cement to obtain passive fit.

In this study, acrylic resin teeth and denture base were bonded to the BioHPP framework instead of using composite veneers. This is because the use of acrylic resin as a veneering material has been suggested to provide greater shock absorption of impact forces on the prosthesis ${ }^{31-33}$. Also, acrylic resin material has low incidence of biological and mechanical complications when used for fullarch hybrid PEEK implant-supported prosthesis ${ }^{12}$. Another reason is the reduced possibility of chipping and fracture veneering material when acrylic resin was used instead of composite resin ${ }^{12,34}$. Furthermore, it is easy to perform adequate lip support and compensate bone resorption and discrepancies in jaw relations with the use of acrylic resin.

The plaque scores increased significantly with time for anterior and posterior implants. The increased plaque accumulation may be attributed to the decreased manual indexterity of old participants causing in reduced cleaning. Although, PEEK has reduced affinity to plaque accumulation, the plaque accumulated around the metal copings. This may be due to the difficulty of cleaning the prosthesis due to presence of acrylic flanges. Also relieve spaces made around the metal copings to avoid gingival traumatization may be responsible for increased plaque accumulation. The plaque around posterior implants was significantly higher than anterior implants. A similar finding was noted by Krennmair et $\mathrm{al}^{35}$ who compared axial and tilted implants supporting All-On-Four mandibular fixed prosthesis. They attributed this finding to the impaired cleaning process of posterior implants caused by prosthesis design (due to presence of cantilever) with excessively close gingival attachment due to the inaccessibility of posterior implant compared to anterior implants. However, the increased plaque accumulation did not cause an increase in gingival inflammation and gingival index over the time.

Pocket depth did not show any significant increase by time. Similarly, Landazurri-Del Barrio and colleagues reported a stable soft tissue situation with a reduction of pocket depths and shallow pockets with no significant midfacial recession in the vast majority of implants with All on four implant rehabilitation ${ }^{36}$. In contrast with this observation, several authors reported an increase in pocket depth around implants supporting "All on four" prosthesis ${ }^{35,37}$. Pocket depth of posterior implants was significantly higher than anterior implants after 12 months. This may be due to increased plaque accumulation and gingival enlargement around posterior implant. Another explanation may be attributed to the surgical technique used for placement of posterior (inclined) implants which necessitate subcrestal merging of the inclined implants with preparation of occlusal flare in the crestal bone to accommodate the multiunit abutments. This may increase bone loss and creates deeper pockets around posterior implants compared to anterior ones.

Resonance frequency analysis was used to evaluate implant mobility as it is noninvasive method that allow verification of implant mobility during healing and in subsequent evaluations ${ }^{38}$. Implant mobility values obtained in all observation times was above 60. No difference in implant mobility was noted between groups or anterior and posterior implants. This may be due to all implants are inserted with high insertion torque with increased bone to implant contact after healing period. The lack of difference in implant mobility 
between anterior (vertical) and posterior (tilted) implants was in line with results of other studies ${ }^{38-40}$.

The amount of marginal bone loss after one year not exceeds $1 \mathrm{~mm}$ for anterior and posterior implants. This rate of bone loss remains within the normal rate which is $1.2 \mathrm{~mm}$ in the first year ${ }^{41-}$ ${ }^{45}$. The most interesting finding of this study is that marginal bone loss around the implants did not increase significantly from T6 to T12. This may be due to vertical bone measurements were made after 6 months of loading with provisional dentures. It is well known that the majority of bone loss occurs within the first year after loading especially the first six months. After 6 months the bone loss could be attributed to the natural biological process of bone remodeling which occurs after implant placement and immediate bone response to healing and reorganization combined with function stresses ${ }^{46}$. Therefore, the rate of bone loss after that decreases. Another reason of reduced bone resorption is the reduced modulus of elasticity of PEEK framework and the use of acrylic resin which dampen the occlusal forces and absorb shock of impact forces on the prosthesis as stated previously ${ }^{31-33}$.

No significant difference of marginal bone loss between anterior and posterior implants was noted at T6 and T12. This may be due to distal inclination of posterior implants that permits for reduction or elimination of the cantilever length, resulting in reduced stresses in the bone around the implants ${ }^{47,48}$. Moreover ,the use of tilted implants increased the anterior-posterior spread, splinting the implants with a rigid superstructure may contribute to a favorable pattern of bone resorption regardless of the axial or tilted implant placement ${ }^{35}$.This was in agreement with Khatami et al who stated that if tilted implants are part of a multiple implantsupported prosthesis, the spread of the implants and rigidity of the prosthesis will reduce or change the nature of bending forces ${ }^{49}$. Similar to these findings, a clinical study by Lopes et al found no difference in bone resorption between vertically and posteriorly tilted fixtures after 5-year ${ }^{50}$.

The limitations of the study included the small sample size, the short evaluation period, the lack of evaluation of clinical and radiographic outcomes in the healing period (after 6 months of loading with provisional denture), and the lack of control group. Therefore, long term randomized trials with sufficient sample size and control group (which include the conventional porcelain fused to metal prothesis) are still needed to ensure the findings of this study.

\section{CONCLUSION}

Within the limitation of this study regarding the small sample size and the short evaluation period, PEEK prosthesis bonded to acrylic resin teeth and denture base can be used successfully to rehabilitate patients with atrophic maxilla with "All on four" concept as it was associated with favourable clinical and radiographic outcomes after one year.

\section{REFERENCES}

1. Branemark PI. Osseointegration and its experimental background. J Prosthet Dent. 1983; 50:399-410.

2. Turkyilmaz I, Company AM, McGlumphy EA. Should edentulous patients be constrained to removable complete dentures? The use of dental implants to improve the quality of life for edentulous patients. Gerodontology. 2010; 27:3-10.

3. Awad MA, Lund JP, Dufresne E, Feine JS. Comparing the efficacy of mandibular implant-retained overdentures and conventional dentures among middle-aged edentulous patients: satisfaction and functional assessment. Int $\mathrm{J}$ Prosthodont. 2003; 16:117-22.

4. Del Fabbro M, Testori T, Francetti L, Weinstein R. Systematic review of survival rates for implants placed in the grafted maxillary sinus. Int J Periodontics Restorative Dent. 2004;24:565-77.

5. Malo P, Rangert B, Nobre M. "All-on-Four" immediatefunction concept with Branemark System implants for completely edentulous mandibles: a retrospective clinical study. Clin Implant Dent Relat Res. 2003;5 Suppl 1:2-9. 
6. Malo P, Rangert B, Nobre M. All-on-4 immediate-function concept with Branemark System implants for completely edentulous maxillae: a 1-year retrospective clinical study. Clin Implant Dent Relat Res. 2005;7 Suppl 1:S88-94.

7. Krekmanov L. Placement of posterior mandibular and maxillary implants in patients with severe bone deficiency: a clinical report of procedure. Int $\mathbf{J}$ Oral Maxillofac Implants. 2000;15:722-30.

8. Pozzi A, Sannino G, Barlattani A. Minimally invasive treatment of the atrophic posterior maxilla: a proof-ofconcept prospective study with a follow-up of between 36 and 54 months. J Prosthet Dent. 2012;108:286-97.

9. Francetti L, Agliardi E, Testori T, Romeo D, Taschieri S, Del Fabbro M. Immediate rehabilitation of the mandible with fixed full prosthesis supported by axial and tilted implants: interim results of a single cohort prospective study. Clin Implant Dent Relat Res. 2008;10:255-63.

10. Malo P, de Araujo Nobre M, Lopes A. The use of computerguided flapless implant surgery and four implants placed in immediate function to support a fixed denture: preliminary results after a mean follow-up period of thirteen months. J Prosthet Dent. 2007;97:S26-34.

11. Malo P, de Araujo Nobre M, Lopes A, Francischone C, Rigolizzo M. "All-on-4" immediate-function concept for completely edentulous maxillae: a clinical report on the medium (3 years) and long-term (5 years) outcomes. Clin Implant Dent Relat Res. 2012;14 Suppl 1:e139-50.

12. Maló P, de Araújo Nobre M, Moura Guedes C, Almeida R, Silva A, Sereno N, et al. Short-term report of an ongoing prospective cohort study evaluating the outcome of fullarch implant-supported fixed hybrid polyetheretherketoneacrylic resin prosthesis and the All-on-Four concept. Clin Implant Dent Relat Res. 2018;20:692-702.

13. Conserva E, Menini M, Tealdo T, Bevilacqua M, Ravera $\mathrm{G}$, Pera F, et al. The use of a masticatory robot to analyze the shock absorption capacity of different restorative materials for prosthetic implants: a preliminary report. Int J Prosthodont. 2009;22:53-5.

14. Hahnel S, Wieser A, Lang R, Rosentritt M. Biofilm formation on the surface of modern implant abutment materials. Clin Oral Implants Res. 2015;26:1297-301.

15. Wang H, Xu M, Zhang W, Kwok DT, Jiang J, Wu Z, et al. Mechanical and biological characteristics of diamond-like carbon coated poly aryl-ether-ether-ketone. Biomaterials. 2010;31:8181-7.
16. Zoidis P, Papathanasiou I, Polyzois G. The Use of a Modified Poly-Ether-Ether-Ketone (PEEK) as an Alternative Framework Material for Removable Dental Prosthesis. A Clinical Report. J Prosthodont. 2016;25:580-4.

17. Rosentritt M, Schneider-Feyrer S, Behr M, Preis V. In Vitro Shock Absorption Tests on Implant-Supported Crowns: Influence of Crown Materials and Luting Agents. Int J Oral Maxillofac Implants. 2018;33:116-22.

18. Zoidis P. The all-on-4 modified polyetheretherketone treatment approach: A clinical report. J Prosthet Dent. 2018;119:516-21.

19. Suwannaroop P, Chaijareenont P, Koottathape N, Takahashi $\mathrm{H}$, Arksornnukit M. In vitro wear resistance, hardness and elastic modulus of artificial denture teeth. Dent Mater J. 2011;30:461-8.

20. Fuhrmann G, Steiner M, Freitag-Wolf S, Kern M. Resin bonding to three types of polyaryletherketones (PAEKs)durability and influence of surface conditioning. Dent Mater. 2014;30:357-63.

21. Keul C, Liebermann A, Schmidlin PR, Roos M, Sener B, Stawarczyk B. Influence of PEEK surface modification on surface properties and bond strength to veneering resin composites. J Adhes Dent. 2014;16:383-92.

22. Malo Bo R, Nobre M. Concept with Brlaanemark System Itextregistered Implants for Completely Edentulous Mandibles : A Retrospective Clinical Study. Implant dentistry. 2003:2-9.

23. Sannino G, Bollero P, Barlattani A, Gherlone E. A Retrospective 2-Year Clinical Study of Immediate Prosthetic Rehabilitation of Edentulous Jaws with Four Implants and Prefabricated Bars. J Prosthodont. 2017; 26:387-94.

24. Galindo DF, Butura CC. Immediately loaded mandibular fixed implant prosthesis using the all-on-four protocol: a report of 183 consecutively treated patients with 1 year of function in definitive prosthesis. The International journal of oral \& maxillofacial implants. 2012;27:628-33.

25. Mombelli A, van Oosten MA, Schurch E, Jr., Land NP. The microbiota associated with successful or failing osseointegrated titanium implants. Oral Microbiol Immunol. 1987;2:145-51.

26. Elsyad MA, Elsaih EA, Khairallah AS. Marginal bone resorption around immediate and delayed loaded implants supporting a locator-retained mandibular overdenture. 
A 1-year randomised controlled trial. J Oral Rehabil. 2014;41:608-18.

27. Elsyad MA, Mahanna FF, Elshahat MA, Elshoukouki AH. Locators versus magnetic attachment effect on periimplant tissue health of immediate loaded two implants retaining a mandibular overdenture: a 1-year randomised trial. J Oral Rehabil. 2016;43:297-305.

28. Elsyad MA, Al-Mahdy YF, Fouad MM. Marginal bone loss adjacent to conventional and immediate loaded two implants supporting a ball-retained mandibular overdenture: a 3-year randomized clinical trial. Clin Oral Implants Res. 2012;23:496-503.

29. Elsyad MA, Khirallah AS. Circumferential bone loss around splinted and nonsplinted immediately loaded implants retaining mandibular overdentures: A randomized controlled clinical trial using cone beam computed tomography. J Prosthet Dent. 2016;116 741-8

30. Seemann R, Marincola M, Seay D, Perisanidis C, Barger N, Ewers R. Preliminary results of fixed, fiber-reinforced resin bridges on four $4-\times 5$-mm ultrashort implants in compromised bony sites: a pilot study. J Oral Maxillofac Surg. 2015;73:630-40.

31. Ciftci Y, Canay S. The effect of veneering materials on stress distribution in implant-supported fixed prosthetic restorations. Int J Oral Maxillofac Implants. 2000; 15:571-82.

32. Davis DM, Rimrott R, Zarb GA. Studies on frameworks for osseointegrated prosthesis: Part 2. The effect of adding acrylic resin or porcelain to form the occlusal superstructure. Int J Oral Maxillofac Implants. 1988; $3: 275-80$.

33. Gracis SE, Nicholls JI, Chalupnik JD, Yuodelis RA. Shock-absorbing behavior of five restorative materials used on implants. Int J Prosthodont. 1991;4:282-91.

34. Jin HY, Teng MH, Wang ZJ, Li X, Liang JY, Wang WX, et al. Comparative evaluation of BioHPP and titanium as a framework veneered with composite resin for implantsupported fixed dental prosthesis. J Prosthet Dent. 2019.

35. Krennmair $S$, Weinländer $M$, Malek $M$, Forstner $T$, Krennmair G, Stimmelmayr M. Mandibular Full-Arch Fixed Prosthesis Supported on 4 Implants with Either Axial Or Tilted Distal Implants: A 3-Year Prospective Study. Clin Implant Dent Relat Res. 2016;18:1119-33.
36. Landázuri-Del Barrio RA, Cosyn J, De Paula WN, De Bruyn H, Marcantonio E. A prospective study on implants installed with flapless-guided surgery using the all-onfour concept in the mandible. Clin Oral Implants Res. 2013;24:428-33.

37. Ayna M, Gulses A, Acil Y. A comparative study on 7-year results of "All-on-Four" immediate-function concept for completely edentulous mandibles: metal-ceramic vs. barretained superstructures. Odontology. 2018;106:73-82.

38. Ayub KV, Ayub EA, Lins do Valle A, Bonfante G, Pegoraro T, Fernando L. Seven-Year Follow-up of Full-Arch Prosthesis Supported by Four Implants: A Prospective Study. The International journal of oral \& maxillofacial implants. 2017;32:1351-8.

39. Balshi SF, Allen FD, Wolfinger GJ, Balshi TJ. A resonance frequency analysis assessment of maxillary and mandibular immediately loaded implants. The International journal of oral \& maxillofacial implants. 2005;20:584-94.

40. Balshi TJ, Wolfinger GJ, Slauch RW, Balshi SF. A retrospective analysis of 800 Branemark System implants following the All-on-Four protocol. Journal of prosthodontics : official journal of the American College of Prosthodontists. 2014;23:83-8.

41. Albrektsson T, Zarb G, Worthington P, Eriksson AR. The long-term efficacy of currently used dental implants: a review and proposed criteria of success. Int $\mathrm{J}$ Oral Maxillofac Implants. 1986;1:11-25.

42. Albrektsson T, Zarb GA. Current interpretations of the osseointegrated response: clinical significance. Int $\mathrm{J}$ Prosthodont. 1993;6:95-105.

43. Zarb GA, Albrektsson T. Consensus report: towards optimized treatment outcomes for dental implants. J Prosthet Dent. 1998;80:641.

44. van Steenberghe D, Quirynen M, Naert I, Maffei G, Jacobs R. Marginal bone loss around implants retaining hinging mandibular overdentures, at 4-, 8- and 12-years follow-up. J Clin Periodontol. 2001;28:628-33.

45. Chung DM, Oh TJ, Lee J, Misch CE, Wang HL. Factors affecting late implant bone loss: a retrospective analysis. Int J Oral Maxillofac Implants. 2007;22:117-26.

46. Hohlweg-Majert B, Metzger MC, Kummer T, Schulze D. Morphometric analysis - Cone beam computed tomography to predict bone quality and quantity. J Craniomaxillofac Surg. 2011;39:330-4. 
47. Bellini CM, Romeo D, Galbusera F. A finite element analysis of tilted versus nontilted implant configurations in the edentulous maxilla.. International, 20092009.

48. Zampelis A, Rangert B, Heijl L. Tilting of splinted implants for improved prosthodontic support: A two-dimensional finite element analysis. The Journal of Prosthetic Dentistry. 2007;97:S35-S43.

49. Khatami AH, Smith CR. "All-on-four" immediate function concept and clinical report of treatment of an edentulous mandible with a fixed complete denture and milled titanium framework. Journal of Prosthodontics. 2008;17:47-51.

50. Lopes A, Malo P, de Araujo Nobre M, Sanchez-Fernandez E, Gravito I. The NobelGuide(R) All-on-4(R) Treatment Concept for Rehabilitation of Edentulous Jaws: A Retrospective Report on the 7-Years Clinical and 5-Years Radiographic Outcomes. Clin Implant Dent Relat Res. 2017;19:233-44. 